\section{Glucose Control and Vascular Outcomes in Type 2 Diabetes: Is the Picture Clear?}

Diabetes Care 2016;39(Suppl. 2):S187-S195 | DOI: 10.2337/dcS15-3023
The overall impact of glucose lowering on vascular complications and major clinical outcomes, including mortality, in type $\mathbf{2}$ diabetes is still an open issue. While intensive glucose control has undoubted benefit for microvascular end points, the relationship between glucose-lowering approaches and reduced incidence and/or progression of macrovascular complications is less clear. This review article will discuss the effect of glucose lowering per se as well as the effects of specific glucose-lowering therapies on vascular outcomes in type 2 diabetes. The role of lifestyle changes on cardiovascular outcomes will be also addressed. Recent analyses from large cardiovascular outcome studies (ACCORD, ADVANCE, and VADT) provide new information on factors that modulate the impact of intensive glucose lowering on outcomes, helping to identify the specific clinical characteristics of the patients receiving the intervention that would show a better response. While several studies on cardiovascular outcomes with diabetes drugs are available, they do not clearly highlight a benefit from using a specific medication or will require additional evidence, as for the sodium-glucose cotransporter 2 blockers.

Vascular complications and cardiovascular disease (CVD) are major causes of morbidity and mortality in people with type 2 diabetes (T2D) (1). The overall impact of glucose lowering on vascular complications in T2D is still debated. The UK Prospective Diabetes Study (UKPDS) was the first trial showing that control of hyperglycemia provides benefit; however, until publication of the extension study the benefit was largely for microvascular end points $(2,3)$. The more recent studies of intensification, Action in Diabetes and Vascular Disease: PreterAx and Diamicron MR Controlled Evaluation (ADVANCE) (4), Action to Control Cardiovascular Risk in Diabetes (ACCORD) (5), and the Veterans Affairs Diabetes Trial (VADT) (6), also showed a decrease in the risk of microvascular end points but not in the primary cardiovascular end point. In ADVANCE, intensive glucose control was defined as use of gliclazide plus any other medication required to achieve an $\mathrm{HbA}_{1 \mathrm{c}}$ of $\leq 6.5 \%$ ( $\leq 48$ $\mathrm{mmol} / \mathrm{mol}$ ) (4) (Table 1). This resulted in a reduction of combined major macrovascular and microvascular events, primarily through reduction in nephropathy. In VADT, patients with suboptimally controlled T2D, 40\% with established CVD, were randomized to either intensive glucose lowering, targeting an absolute reduction of $1.5 \%$ (16 mmol/mol) $\mathrm{HbA}_{1 \mathrm{c}}$, or standard therapy (Table 1). After follow-up of 5.6 years, intensive glucose control prevented the increase in albuminuria but without significant difference in major cardiovascular events or all-cause mortality (6). ACCORD (5) (Table 1) randomized 10,251 participants with T2D to either intensive therapy targeting an $\mathrm{HbA}_{1 \mathrm{c}}$ level $<6.0 \%$ (42 $\mathrm{mmol} / \mathrm{mol}$ ) or standard therapy targeting $\mathrm{HbA}_{1 \mathrm{c}}$ between 7.0 and $7.9 \%$ (53 and $63 \mathrm{mmol} / \mathrm{mol}$ ). The primary outcome, $\mathrm{a}$ composite of nonfatal myocardial infarction (MI), nonfatal stroke, or death from
${ }^{1}$ Section of Internal Medicine, Endocrinology, Andrology and Metabolic Diseases, Department of Emergency and Organ Transplantation, University of Bari Aldo Moro, Bari, Italy ${ }^{2}$ Institute for Cellular Medicine-Diabetes, Newcastle University, Newcastle-upon-Tyne, U.K. ${ }^{3}$ Chronic Disease Prevention Unit, National Institute for Health and Welfare, Helsinki, Finland ${ }^{4}$ Center for Vascular Prevention, Danube-University Krems, Krems, Austria

${ }^{5}$ Dasman Diabetes Institute, Dasman, Kuwait

${ }^{6}$ Diabetes Research Group, King Abdulaziz University, Jeddah, Saudi Arabia

Corresponding author: Francesco Giorgino, francesco. giorgino@uniba.it.

This publication is based on the presentations at the 5th World Congress on Controversies to Consensus in Diabetes, Obesity and Hypertension (CODHy). The Congress and the publication of this supplement were made possible in part by unrestricted educational grants from AstraZeneca.

(c) 2016 by the American Diabetes Association. Readers may use this article as long as the work is properly cited, the use is educational and not for profit, and the work is not altered. 


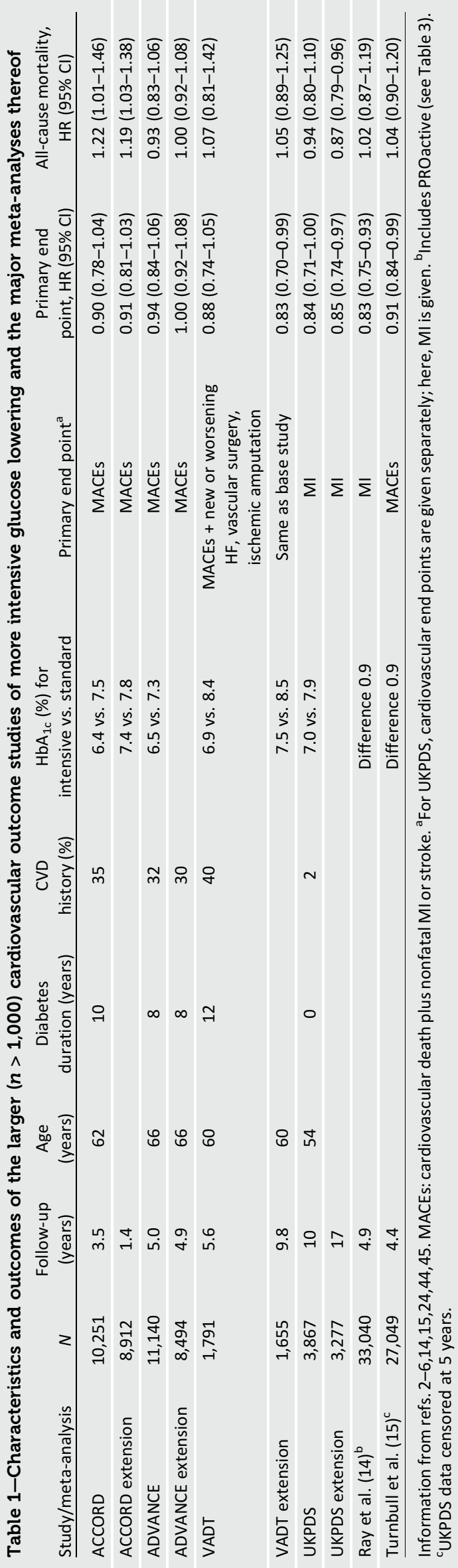

cardiovascular causes (major adverse cardiovascular events [MACEs]), occurred similarly in the two arms, although the arm of intensive therapy showed lower rates of nonfatal $\mathrm{Ml}$ and higher rates of all-cause and cardiovascular mortality when prematurely stopped after 3.5 years. In ACCORD, intensive therapy delayed the onset of albuminuria and some measures of eye complications and neuropathy $(7,8)$.

Other key studies have explored the impact of specific drug therapy on cardiovascular end points rather than through controlling hyperglycemia per se. In these studies, some degree of glycemic equipoise occurs, intended or otherwise, owing to extra use of other glucose-lowering therapies in the placebo arm. The PROspective PioglitAzone Clinical Trial in macrovascular Events (PROactive) assessed pioglitazone in people with TD2 with evidence of macrovascular disease (9). The broad primary cardiovascular end point was not significantly different compared with standard care, but the "main" secondary end point of all-cause death, stroke, and MI was significantly decreased by $16 \%$. Participants with previous $\mathrm{MI}$ showed greater reductions of fatal/nonfatal MI by $28 \%$ and acute coronary syndrome by $37 \%(10)$. In the Outcome Reduction With Initial Glargine Intervention (ORIGIN) study (11), using insulin glargine in a large cohort of individuals with $T 2 D$, impaired fasting glucose (IFG), or impaired glucose tolerance (IGT), all with multiple cardiovascular risk factors, there was no effect on MACEs or these events plus revascularization or hospitalization for heart failure (HF) over 6.2 years.

Both use of a combined pharmacological approach to aggressively correct hyperglycemia and trials of a specific medication are associated with hypoglycemia and weight gain, either of which might have countered any benefit from $\mathrm{HbA}_{1 \mathrm{c}}$ reduction. However, the Look AHEAD (Action for Health in Diabetes) study (12), exploring the effects of decreased caloric intake and increased physical activity in individuals with T2D, showed no benefit on cardiovascular outcome over $>13$ years.

\section{Reducing $\mathrm{HbA}_{1 \mathrm{c}}$ to Target: How and With Which Risks and Benefits? \\ Adverse Effects of Intensive Glucose Lowering}

Building on the individual outcome studies, meta-analyses have assessed the 
potential benefit of intensive glucose lowering on mortality and cardiovascular events in T2D (13-17), generally showing limited benefit for mortality, an $\sim 10 \%$ reduction in the risk of microalbuminuria, and a $15-20 \%$ reduction in the incidence of nonfatal $\mathrm{Ml}$ - these for an average glucose lowering of $\sim 1.0 \%$ (11 $\mathrm{mmol} / \mathrm{mol}$ ) $\mathrm{HbA}_{1 \mathrm{c}}$. A $16-20 \%$ reduction in $\mathrm{Ml}$ in the intensive compared with standard therapy group was recently reported in ACCORD (18). The relatively limited benefits of intensive glucose lowering on macrovascular outcomes and mortality can partly be explained by good glucose control in the standard arms, inclusion of people with long-standing T2D and advanced vascular damage, concomitant control of other cardiovascular risk factors, aggressive medication regimens associated with risk of hypoglycemia and weight gain, and drug-drug interactions (19). Indeed, established CVD may have dampened the benefits of intensive glycemic control in the high-risk cohorts of ACCORD, ADVANCE, and VADT, all with a long duration of T2D (10 years) compared with the newly diagnosed population in UKPDS.

The role of hypoglycemia as contributing to excess mortality is debated. Specifically, it is unclear whether hypoglycemia has a causal effect or simply identifies frail individuals. Rates of hypoglycemia were increased in the intensive therapy groups of ACCORD, ADVANCE, and VADT (10.5 vs. $3.5,2.7$ vs. 1.5 , and 21.2 vs. $9.9 \%$, respectively) (4-6). Unfortunately monitoring of hypoglycemia in these trials was relatively crude and did not include detailed data that could help with understanding the issues. Biological mechanisms have been proposed for any causative role for hypoglycemia in CVD outcomes, including catecholamine release increasing myocardial workload (20), electrocardiogram QT-interval lengthening predisposing to ventricular tachycardia (21), increased vascular inflammation (raised C-reactive protein, interleukin-6 and -8 , tumor necrosis factor $-\alpha$, and endothelin-1) potentiating endothelial dysfunction and thrombotic risk (20), and perhaps increased vessel wall stiffness (22). However, post hoc and followup analyses from ACCORD and ADVANCE have questioned hypoglycemia as a causative factor for mortality with intensive glucose lowering. In ACCORD, severe hypoglycemia was associated with a higher risk of death in the standard rather than intensive therapy arm ( 4.5 vs. $2.8 \%$ ) (23). Moreover, the excess deaths in the intensive arm persisted after further followup of 1.3 years in spite of convergence of diabetes therapy and $\mathrm{HbA}_{1 \mathrm{c}}$ (24). Similar conclusions were drawn from ADVANCE (25). The ACCORD Memory in Diabetes (ACCORD-MIND) trial found on brain MRI that symptomatic severe hypoglycemia was not associated with brain atrophy or white matter abnormalities (26). In ACCORD, severe episodes of hypoglycemia occurred more frequently in individuals with poor cognitive function and were frequently preceded by change in food intake $(27,28)$. A similar association between severe cognitive dysfunction and severe hypoglycemia emerges from ADVANCE (29). These results suggest that cognitive function assessment and education programs might be indicated to potentially prevent hypoglycemia in patients with T2D. Severe hypoglycemia was associated with insulin deficiency, anti-islet autoimmunity, and baseline insulin use, suggesting that $\mathrm{C}$-peptide levels and islet autoantibodies may serve as biomarkers for risk of severe hypoglycemia (30).

Weight gain is also associated with intensive glucose control. The ACCORD intensive therapy group gained $3.5 \mathrm{~kg}$ compared with $0.4 \mathrm{~kg}$ in the standard group (5), while in VADT the gain was 8.2 vs. $4.1 \mathrm{~kg}(6)$. Significant weight gain in the insulin/sulfonylurea arm was observed in UKPDS (2). In ACCORD, reduction of $\mathrm{HbA}_{1 \mathrm{c}}$ from baseline was associated with weight gain only when baseline $\mathrm{HbA}_{1 \mathrm{c}}$ was high, and in both ACCORD and ADVANCE beginning a thiazolidinedione or insulin was particularly associated with weight gain $(31,32)$. The clinical significance of such weight gain is unclear, as both peroxisome proliferator-activated receptor- $\gamma$ agonists and insulin are associated with increased insulin sensitivity.

\section{$H b A_{1 c}$ Targets in Specific Subgroups}

It has been noted that the populations studied, particularly in ACCORD and VADT, do not necessarily represent the average person with T2D as seen in ambulatory care. The study participants had 10-year disease duration or more, elevated $\mathrm{HbA}_{1 \mathrm{c}}$ at baseline (i.e., 8.29.4\% [66-79 $\mathrm{mmol} / \mathrm{mol}])$, and established CVD or multiple risk factors $(5,6)$. This has led to the hypothesis that the benefits of intensive glycemic control on macrovascular outcomes can be observed only in newly diagnosed T2D and after a long duration of intervention, as indeed seen in UKPDS (2). In agreement, a substudy of 301 participants with T2D in VADT showed a better effect of intensive compared with standard therapy to reduce cardiovascular events in people without computed tomography-detectable coronary artery calcification, a benefit lost with higher calcification score (33). In contrast, intensive glycemic control significantly increases the risk of cardiovascular and allcause mortality in T2D patients with mild/ moderate chronic kidney disease (34).

Current recommendations suggest that more stringent goals $\left(\mathrm{HbA}_{1 \mathrm{c}}<6.0\right.$ $6.5 \%$ [ $<42-48 \mathrm{mmol} / \mathrm{mol}]$ ) might further reduce complications in people with long life expectancy without documented macrovascular disease and/or if drugs not causing hypoglycemia are used. Moreover, glycemic goals should be pursued with caution in people with severe or frequent hypoglycemia. Aiming for an $\mathrm{HbA}_{1 \mathrm{c}}$ of $7.0-8.5 \%$ (53-69 $\mathrm{mmol} / \mathrm{mol}$ ) may be reasonable in people with very long diabetes duration, a history of severe hypoglycemia, advanced atherosclerosis, significant comorbidities, frailty, and limited life expectancy (35-38). However, it is not clear with what priority these criteria should be implemented and how to plan conduct when multiple elements are present. Tight glucose control will need to be maintained for $>3-5$ years to yield benefit. In ACCORD, excess mortality was found in those who showed an increase in $\mathrm{HbA}_{1 \mathrm{c}}$ with intensive glucose control (39); thus, people with worsening glycemic control when exposed to intensive treatment should be set less stringent glucose targets. Additionally, intensive treatment was associated with improved primary outcomes in people with low and moderate hemoglobin glycation index $(\mathrm{HGI})(\mathrm{HGI}=$ observed $\mathrm{HbA}_{1 \mathrm{c}}$ - predicted $\mathrm{HbA}_{1 \mathrm{c}}$ ) but not with high $\mathrm{HGl}$ at baseline, and higher total mortality in intensively treated patients was confined to the high-HGI subgroup (40). A high HGI was also associated with greater risk for hypoglycemia (40). Finally, a retrospective subgroup analysis of the ACCORD data set, assessing the impact and tolerability of intensive glucose management in older versus younger adults ( $\geq 65$ vs. $<65$ years), showed a $71 \%$ increased risk of cardiovascular 
mortality in the intensive arm for the younger subgroup (41). However, older participants in the ACCORD trial were people in community/ambulatory care and not frail/disabled or institutionalized. A list of factors that may help in individualizing $\mathrm{HbA}_{1 \mathrm{c}}$ targets is given in Table 2.

Long-term Effects of Reducing $\mathrm{HbA}_{1 \mathrm{c}}$ In ADVANCE, but not ACCORD, intensive glucose lowering showed benefit for surrogate end points of renal damage (microalbuminuria and macroalbuminuria or progression/regression of albuminuria) but also for renal outcomes (end-stage renal disease) (7,42). In UKPDS, the effects of tighter blood glucose control on Ml took years to become evident and statistically significant, including for metformin (3). Even all-cause mortality eventually reached statistical significance after 17 years, though caution is needed in interpreting that result.

As our perspective on glucose control should be long-term, consistency of $\mathrm{HbA}_{1 \mathrm{c}}$ and glucose targets over time becomes important, since variability of these measures is associated with higher risk of vascular events and mortality, as shown in ADVANCE (43). More recently, long-term results from ACCORD, ADVANCE, and VADT, describing results over the years after a previous period of intensive glucose lowering, have become available $(24,44,45)$. In ADVANCE, after 5.4 years follow-up with no evident between-group differences in $\mathrm{HbA}_{1 \mathrm{c}}$, no differences were observed in the risk of all-cause or cardiovascular death between study cohorts (44). However, in VADT, with follow-up of $\sim 10$ years, a $17 \%$ lower risk of the primary outcome in the prior intensive glucose-lowering arm was noted, but total mortality and cardiovascular mortality were unchanged (45). The 5-year outcomes of 3.7 years of intensive glucose lowering in ACCORD showed trends for excess mortality and reduced nonfatal $\mathrm{MI}$ similar to those during the active intervention period. Altogether, these findings suggest that aggressive glucose lowering does not reduce mortality in the medium term in cohorts of individuals with advanced T2D and CVD. The benefit of previous intensive glucose control to reduce macrovascular complications in follow-up was confirmed in ACCORD and emerged in VADT but was

Table 2-Potential criteria for individualization of glucose targets in T2D $\mathrm{HbA}_{1 \mathrm{c}}<6.5-7.0 \%$ $\mathrm{HbA}_{1 \mathrm{c}} 7.0-8.0 \%$

\begin{tabular}{lcc}
\hline Individual preference & High input/motivation & Higher short-term focus \\
Age (years) & $<55$ & $>55$ \\
Diabetes duration (years) & $<10$ & $>10$ \\
Life expectancy (years) & $>5$ & $<5$ \\
Possible to perform IGC for $>5$ years & Yes & No \\
Usual HbA $1 \mathrm{c}$ level (\%) & $<8.0$ & $>8.0$ \\
CVD & No & Yes \\
Prone to hypoglycemia (cognitive & & Yes \\
dysfunction, insulin deficiency) & No & No \\
Reduction of $\mathrm{HbA}_{1 \mathrm{c}}$ level upon IGC & Yes & High \\
\hline HGI & Low/moderate &
\end{tabular}

Information from refs. 3-6, 25-30,40. IGC, intensive glucose control.

not apparent in ADVANCE. Variations in participant characteristics, in-trial differences in $\mathrm{HbA}_{1 \mathrm{c}}$ between arms, duration of follow-up, $\mathrm{HbA}_{1 \mathrm{c}}$ trends, and management of other cardiovascular risk factors may explain the diverse findings in these posttrial extensions.

\section{What Is the Role of Lifestyle Intervention?}

The results from T2D prevention studies have been very positive in terms of preventing or delaying the development of T2D (46). The question here is, rather, whether such lifestyle intervention also prevents CVD and related events. However, none of these studies were designed or powered for CVD outcome evaluation. Nevertheless, they have provided useful information about the prevention of CVD in the high-risk group with IGT. Three types of information have been published

1. CVD mortality was significantly decreased in the former intervention group compared with the former control group in the Chinese Da Qing Diabetes Prevention Study (47). This difference started to be visible after 10 years from randomization (4 years after the intervention program had been stopped) and became statistically significant by the 23-year follow-up.

2. The Swedish Malmö Feasibility Study in middle-aged men with IGT provided lifestyle intervention and compared CVD outcomes with data from men who did not take up the interventions offered (48). CVD mortality was lower in the participants in the intervention arm and, indeed, almost similar to that in normoglycemic men from the original screened population.

3. The Finnish Diabetes Prevention Study (DPS) (51) gave results similar to those of the Swedish study. Outcomes of participants to the DPS were compared with those from a population survey using similar methods $(49,50)$. The results showed that people with IGT in the DPS had significantly lower CVD incidence and mortality than in people with IGT in the survey cohort. Indeed, total mortality was $>50 \%$ lower in the DPS cohort than in normoglycemic people in the background population, although prevalence of the metabolic syndrome was almost identical at baseline (51).

In line with the Diabetes Epidemiology: Collaborative Analysis of Diagnostic Criteria in Europe (DECODE) data $(52,53)$, there was no indication in the DPS that a single measurement of fasting plasma glucose is useful for prediction of CVD risk (54). There is no evidence that people with IFG will benefit from lifestyle intervention, the only study in those with isolated IFG being negative (55). Thus, measurement of fasting plasma glucose for the assessment of CVD risk is not justified, consistent with the recommendations provided in the current European guideline on diabetes, prediabetes, and CVD (56).

In addition to the lifestyle intervention trials, the Study to Prevent NIDDM (STOPNIDDM) using acarbose as the intervention in individuals with IGT showed a statistically significant reduction in CVD rates (57) but with few CVD events. A further 
study is ongoing in China (58). In the Nateglinide And Valsartan in Impaired Glucose Tolerance Outcomes Research (NAVIGATOR) study, involving 9,306 individuals with IGT, participants with CVD or one or more additional cardiovascular risk factors were randomized to receive nateglinide, valsartan, or placebo and followed for CVD events (cardiovascular mortality, nonfatal stroke, or MI [MACEs]) for 6 years (59). Pedometer-assessed baseline ambulatory activity and change in ambulatory activity at 12 months were inversely associated with CVD events (60). Results for change in ambulatory activity were unaffected after adjustment for changes in BMI and other potential confounding variables at 12 months.

In contrast, in people with T2D the effects of intensive lifestyle intervention using decreased calorie intake and increased physical activity showed no benefit on the primary outcome (MACEs or hospitalization for angina) over a followup of $>13$ years in spite of greater weight loss, lower $\mathrm{HbA}_{1 \mathrm{c}}$ levels, and early improvement in multiple cardiovascular risk factors (12).

\section{Does Choice of Glucose-Lowering Therapy Matter?}

The evidence on glucose-lowering therapy and cardiovascular outcomes, reviewed above, leaves open the question as to what medication might be chosen to improve outcomes or to avoid adverse events. Even after 50 years of use of three of the classes of glucose-lowering therapies, the answer is uncertain. Newer therapies in three drug classes have been tested recently, but study design will probably lead to some clinical confusion and debate for reasons like populations studied and comparator therapies.

Widespread use of glucose-lowering therapies should allow examination of their performance in routine clinical practice. However, observational studies lack suitability for this, except perhaps in a hypothesis setting (61). The major problem is that the circumstances of prescription (e.g., ambulatory care, referral to secondary care, hospital admission) and the prescriber (e.g., primary health care, diabetologist, tertiary care) should have very large effects on outcomes, dwarfing differences between drug classes, but are not generally ascertained. Because of the stepped algorithm for glucose-lowering therapy, with preference of order for some classes before others, and because of contraindications associated with vascular disease, biases related to comorbidities are likely to be large.

Understanding of pathogenetic mechanisms can be useful to explain a known issue, such as hypoglycemia with sulfonylureas. However, where an in vitro finding might suggest a speculative effect (e.g., sulfonylureas and cardiac ion channels, insulin and arterial cell wall proliferation), the prior probability of a clinically significant issue is little changed, despite our innate drive to use weak knowledge. Presently, understandings of mechanisms of efficacy are poor-that of metformin is still disputed, as is control of hepatic glucose output by insulin.

Thus, only evidence from randomized controlled trials (RCTs) is presently of value in determining clinical practice. However, the RCT evidence is of limited fit for purpose, mainly owing to difficulties regarding generalizability to typical populations with diabetes.

\section{Metformin}

Metformin is first line in therapy algorithms, combining effective glucose lowering with weight neutrality and no hypoglycemia (62). The RCT evidence for vascular protection comes from a substudy of UKPDS in which it was mostly used as monotherapy and not as per current practice (63). The overweight substudy numbers investigated were small ( $n=753$ ), and despite long duration of follow-up (10.7 years), so were events ( $\mathrm{MI}, n=112$; 39 on metfor$\mathrm{min})$. The estimate of reduction of MI was good, but the Cls were large; the upper bound (0.89) overlaps the central estimate for sulfonylureas/insulin (Table 3). The follow-on study showed some loss of effect, suggestive of regression to the mean. The conclusion is that metformin gives vascular protection in monotherapy but that the extent of this is unknown and not different from sulfonylureas and insulin. Use of metformin in ADOPT (A Diabetes Outcome Progression Trial), and as a comparator to rosiglitazone use in RECORD (Rosiglitazone Evaluated for Cardiovascular Outcomes in Oral Agent Combination Therapy for Type 2 Diabetes), is discussed below; these studies do not suggest that metformin differs from other medications in cardiovascular protection.

\section{Sulfonylureas}

Sulfonylureas were major components of the UKPDS (2). However, the primary result was analyzed together with basal insulin therapy, complicating interpretation of the results. For this combined group, the effect on MI became mired in uncertainty, but an upper bound of 1.00 of the $95 \% \mathrm{Cl}$ against conservative therapy suggests caution in deciding the probability of vascular protection (Table 3). However, in the extension phase, with larger numbers of events and no change in the central estimate of risk reduction (15\%), the Cls shrink to $0.74-$ 0.97 , suggesting benefit and not harm. There was also a statistically significant reduction in all-cause mortality (3) (Table 3).

In ADOPT, with vascular outcomes a secondary safety outcome and relatively small numbers (e.g., $5 \%$ of 1,441 participants in the sulfonylurea cohort), glibenclamide outperformed both metformin and rosiglitazone with regard to $\mathrm{MI}(64,65)$. In RECORD, where half the participants were randomized to sulfonylureas versus rosiglitazone, vascular outcomes were identical and by extension similar to metformin (66) (Table 3). In ADVANCE, although not a study of specific therapies, the primary glucose-lowering intervention choice was gliclazide; as the central estimate of effect on vascular outcomes was $<1.00$ and the upper $\mathrm{Cl}$ only 1.06 , an adverse effect of the sulfonylurea is denied (4).

\section{Acarbose}

Post hoc meta-analysis of seven RCTs with acarbose in 2,180 people with T2D and $\geq 1$ year follow-up (67) suggested decrease in $\mathrm{MI}$ and any CVD. A definitive RCT seems warranted (58).

\section{Peroxisome Proliferator-Activated} Receptor- $\gamma$ Agonists

Vascular outcome studies after licensing were mandated by the European authorities because of HF concerns. For pioglitazone, the 3-year PROactive study had a composite vascular end point that was not statistically significant due to the inclusion of peripheral arterial interventions, which diverged from the usual cardiovascular study outcomes (9) (Table 3). A secondary analysis (prespecified shortly before study completion) of 


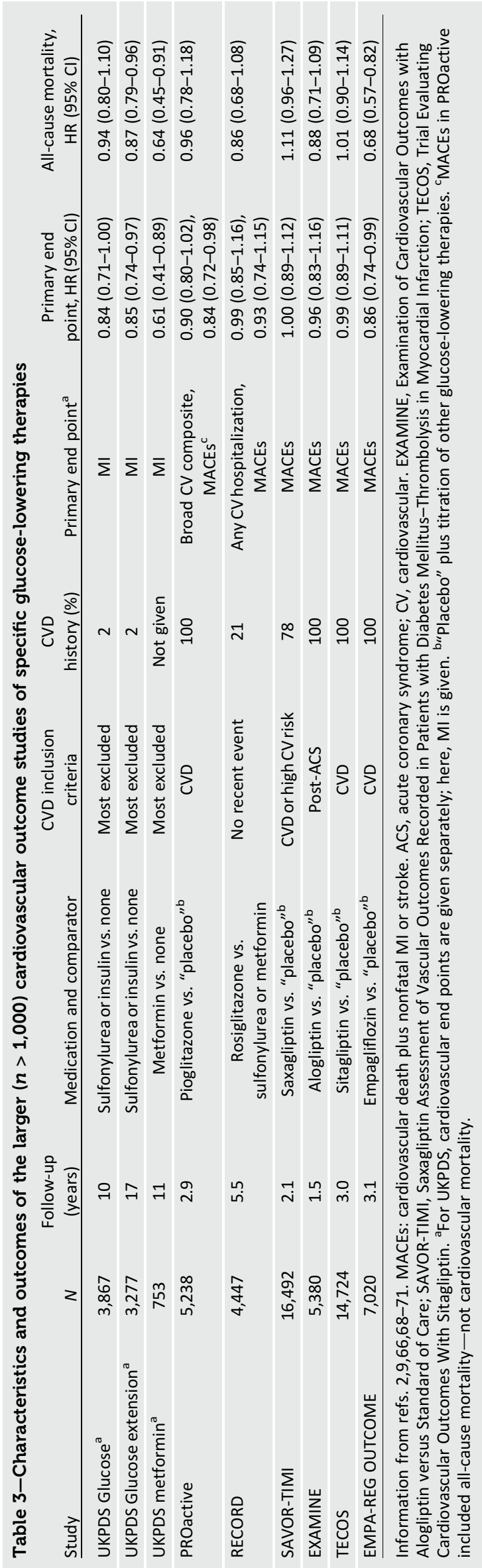

the classic MACEs, but using all-cause mortality, did provide evidence of vascular protection (95\% Cl 0.72-0.98). One difficulty, which also affects several current cardiovascular outcome trials, is that the comparator arm was investigatordiscretion standard of care (described misleadingly as "placebo"), meaning that it is unclear what pioglitazone was being compared with. Indeed, pioglitazone has good glucose-lowering efficacy, but the $\mathrm{HbA}_{1 \mathrm{c}}$ difference at end point was $0.5 \%$ ( $5 \mathrm{mmol} / \mathrm{mol}$ ), suggesting efficacy of other medications in the placebo group; if these were beneficial, then the pioglitazone effect is greater than described, and, if adverse, lesser.

Secondary data for rosiglitazone as monotherapy are available for myocardial ischemia from ADOPT, with results similar to those of metformin but worse than those of glibenclamide $(64,65)$. In RECORD, over 5 years, rosiglitazone was compared with metformin and sulfonylureas, all as dual therapy (66). Cardiovascular outcomes were not worse than these, including all-cause mortality (RR 0.86 [95\% Cl 0.68-1.08]) and MACEs (0.93 [0.74-1.15]) and against the two comparators individually. The exception was HF, increased by $\sim 1$ in every 400 person-years, though including HF with MACEs still gave equivalence $(0.99$ [0.81-1.20]). Because a small and flawed meta-analysis of early rosiglitazone studies gave an adverse result, the RECORD study data were reanalyzed independently and not found wanting (68).

Incretin-Based Therapies and SodiumGlucose Cotransporter 2 Blockers

No definite information is yet available as to whether dipeptidyl peptidase 4 inhibitors or GLP-1 receptor agonists (GLP-1RAs) offer cardiovascular advantage as glucose-lowering agents, except by extension from glucose-lowering results with other agents in UKPDS and $\operatorname{ACCORD}(2,5)$ and the meta-analyses of such studies (13-17). Although cardiovascular outcome studies have been reported, they have been performed in high-risk populations for short periods of time as safety studies and suffer the same problem of pseudo-placebo comparators as discussed for pioglitazone (69-71) (Table 3). In some studies, glycemic equipoise was an aim (equal glucose control in the two arms to test 
medication differences only) but not achieved (71).

For sodium-glucose cotransporter 2 (SGLT-2) blockers, a similar situation pertains, in that the only reported study (BI 10773 [Empagliflozin] Cardiovascular Outcome Event Trial in Type 2 Diabetes Mellitus Patients [EMPA-REG OUTCOME]) is in people with prior CVD and had an unusually high initial event rate (72). The primary objective was a significant reduction of MACEs (hazard ratio [HR] 95\% $\mathrm{Cl} 0.74-0.99)$, but its components of cardiovascular death, MI, and stroke behaved very differently. While cardiovascular mortality was reduced significantly in the empagliflozin group (95\% $\mathrm{Cl} 0.49-0.77, P<0.001$ ), it was a secondary outcome when considered alone, and it is unclear that this is related to classic cardiac events or more specifically to improvement of $\mathrm{HF}(95 \% \mathrm{Cl} 0.50-0.85$ for hospitalization). It is unlikely that the results were due to glucose lowering. Stroke incidence was not reduced (95\% Cl 0.89-1.56) despite significant fall in blood pressure with empagliflozin.

Both SGLT-2 blockers and GLP-1RAs might be expected to affect the fundamental defect of T2D in the liver by improving net substrate load (calorie balance) and, as a result, improving features of that defect (metabolic syndrome, fatty liver, inflammation) that are associated with CVD. Therapies that produce a negative calorie balance may well show advantage additional to that of glucose lowering in time. Such a comment has little relevance on probability of clinical cardiovascular advantage until further RCT results are available.

\section{Insulin Therapy}

The RCT evidence regarding insulin is not easy to interpret. In UKPDS, insulin was part of the major glucose-lowering interventions used as monotherapy (though discontinued by $30 \%$ of those randomized to it and not titrated intensively); the conclusions above from that study for sulfonylureas apply in part to insulin (2). In ACCORD, insulin was a major part of the group of therapies showing cardiovascular advantage for ischemic heart disease when the study was stopped prematurely but impossible to separate from them $(5,18)$. A post hoc analysis of different therapies

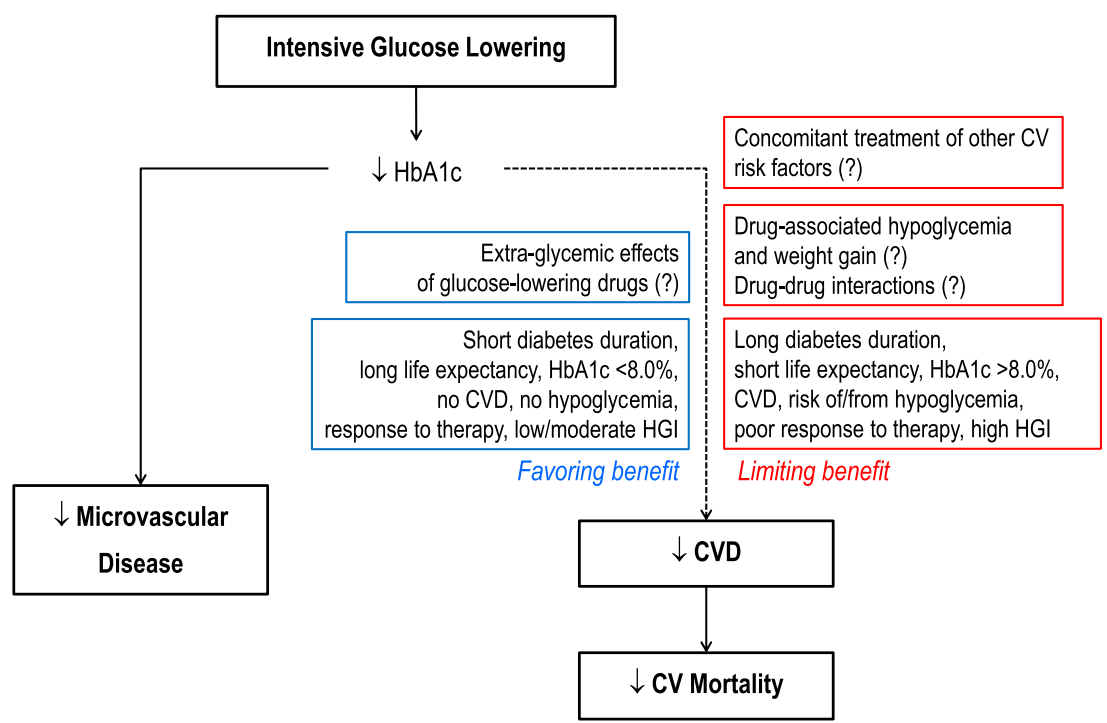

Figure 1-Relationship between intensive glucose control and vascular complications in T2D. CV, cardiovascular.

was shown in the initial ACCORD results' presentation but has never been published. The ORIGIN results are discussed in the first section of this review (11), but here again the comparators are a mix of other agents, with little separation in $\mathrm{HbA}_{1 \mathrm{c}}$ and at levels close to the diagnostic cutoff for diabetes.

\section{Conclusions}

The findings from UKPDS, ACCORD, ADVANCE, and VADT have provided important insights into the balance of benefits and risks associated with the use of glucose control in people with T2D. However, the relationship between control of hyperglycemia and cardiovascular risk remains relatively controversial, and evidence that intensive antihyperglycemic therapy will reduce mortality in T2D patients in the long-term is evident in some but not in all studies. Individualization of therapy then becomes important and should be implemented based on multiple factors, including diabetes duration, preexisting CVD, hypoglycemia risk, comorbidities, response to therapy, frailty, and other factors (Fig. 1). While lifestyle intervention may reduce CVD outcomes in individuals with IGT, such evidence in overt T2D is still lacking. Nevertheless, healthy diet and physical activity do not result in harmful effects and can be associated with other benefits besides CVD prevention.

The evidence for the cardiovascular benefit of any one class of glucoselowering medications compared with any other is also weak at present. This may potentially change if the medications that improve calorie balance (i.e., SGLT-2 blockers and GLP-1RAs) turn out to change the metabolic milieu to a degree that will improve the underlying mechanisms of T2D and CVD. The recent results from the trial with empagliflozin are interesting and promising, but we need to wait for results from other ongoing trials with SGLT-2 blockers in order to understand whether they really reduce CVD risk in T2D patients or affect predominantly cardiovascular mortality and worsening HF. Choice of therapies to achieve optimal outcomes is still largely to be based not on comparative vascular outcomes but on other features such as tolerability (hypoglycemia, gastrointestinal side effects, body weight gain), safety, cost, and convenience.

Duality of Interest. F.G. has served on an advisory panel for AstraZeneca, Bristol-Myers Squibb, Eli Lilly, Roche Pharmaceuticals, Takeda Pharmaceutical Company, and Janssen Pharmaceuticals; has served as a consultant for AstraZeneca, Bristol-Myers Squibb, Boehringer Ingelheim, LifeScan Animas, Merck Sharp \& Dohme (MSD), Novo Nordisk, and Sanofi; and has received research support from AstraZeneca, Bristol-Myers Squibb, Eli Lilly, LifeScan Animas, and Sanofi. P.D.H. has served on an advisory panel for AstraZeneca, Antriabio, GlaxoSmithKline, Janssen, MSD, Novo Nordisk, Roche Diagnostics, Sanofi, and Skyepharma; has received speaking honoraria for AstraZeneca, Biocon, Eli Lilly, MSD, Novo Nordisk, and Sanofi; and has 
received research support from GlaxoSmithKline, MSD, Novo Nordisk, Sanofi, and Skyepharma. J.T. reports grants and fees from AstraZeneca, grants and fees from Bayer HealthCare Pharmaceuticals, grants from Boehringer Ingelheim, fees from Eli Lilly, fees from Impeto Medical, grants and fees from Merck Serono, grants and fees from MSD, fees from Novo Nordisk, grants and fees from Novartis, grants and fees from Sanofi, and grants from Servier outside the submitted work and owns shares from Orion Pharma. No other potential conflicts of interest relevant to this article were reported.

\section{References}

1. Fox CS, Coady S, Sorlie PD, et al. Increasing cardiovascular disease burden due to diabetes mellitus: the Framingham Heart Study. Circulation 2007;115:1544-1550

2. UK Prospective Diabetes Study (UKPDS) Group. Intensive blood-glucose control with sulphonylureas or insulin compared with conventional treatment and risk of complications in patients with type 2 diabetes (UKPDS 33). Lancet 1998;352:837-853

3. Holman RR, Paul SK, Bethel MA, Matthews DR, Neil HA. 10-year follow-up of intensive glucose control in type 2 diabetes. N Engl J Med 2008;359:1577-1589

4. Patel A, MacMahon S, Chalmers J, et al.; ADVANCE Collaborative Group. Intensive blood glucose control and vascular outcomes in patients with type 2 diabetes. N Engl J Med 2008; 358:2560-2572

5. Gerstein $\mathrm{HC}$, Miller ME, Byington RP, et al.; Action to Control Cardiovascular Risk in Diabetes Study Group. Effects of intensive glucose lowering in type 2 diabetes. N Engl J Med 2008; 358:2545-2559

6. Duckworth W, Abraira C, Moritz T, et al.; VADT Investigators. Glucose control and vascular complications in veterans with type 2 diabetes. N Engl J Med 2009;360:129-139

7. Ismail-Beigi F, Craven T, Banerji MA, et al.; ACCORD trial group. Effect of intensive treatment of hyperglycaemia on microvascular outcomes in type 2 diabetes: an analysis of the ACCORD randomised trial. Lancet 2010;376: 419-430

8. Chew EY, Ambrosius WT, Davis MD, et al.; ACCORD Study Group; ACCORD Eye Study Group. Effects of medical therapies on retinopathy progression in type 2 diabetes. N Engl J Med 2010;363:233-244

9. Dormandy JA, Charbonnel B, Eckland DJ, et al.; PROactive investigators. Secondary prevention of macrovascular events in patients with type 2 diabetes in the PROactive Study (PROspective pioglitAzone Clinical Trial In macroVascular Events): a randomised controlled trial. Lancet 2005;366: 1279-1289

10. Erdmann E, Dormandy JA, Charbonnel B, Massi-Benedetti M, Moules IK, Skene AM; PROactive Investigators. The effect of pioglitazone on recurrent myocardial infarction in 2,445 patients with type 2 diabetes and previous myocardial infarction: results from the PROactive (PROactive 05) Study. J Am Coll Cardiol 2007;49: 1772-1780

11. Gerstein HC, Bosch J, Dagenais GR, et al.; ORIGIN Trial Investigators. Basal insulin and cardiovascular and other outcomes in dysglycemia. N Engl J Med 2012;367:319-328

12. Wing RR, Bolin P, Brancati FL, et al.; Look AHEAD Research Group. Cardiovascular effects of intensive lifestyle intervention in type 2 diabetes. N Engl J Med 2013;369:145-154

13. Boussageon $R$, Bejan-Angoulvant $T$, Saadatian-Elahi $\mathrm{M}$, et al. Effect of intensive glucose lowering treatment on all cause mortality cardiovascular death, and microvascular events in type 2 diabetes: meta-analysis of randomised controlled trials. BMJ 2011;343:d4169

14. Ray KK, Seshasai SR, Wijesuriya S, et al. Effect of intensive control of glucose on cardiovascular outcomes and death in patients with diabetes mellitus: a meta-analysis of randomised controlled trials. Lancet 2009;373 1765-1772

15. Turnbull FM, Abraira C, Anderson RJ, et al.; Control Group. Intensive glucose control and macrovascular outcomes in type 2 diabetes. $\mathrm{Di}$ abetologia 2009;52:2288-2298

16. Hemmingsen B, Lund SS, Gluud C, et al. Intensive glycaemic control for patients with type 2 diabetes: systematic review with metaanalysis and trial sequential analysis of randomised clinical trials. BMJ 2011;343:d6898

17. Hemmingsen B, Lund SS, Gluud C, et al. Targeting intensive glycaemic control versus targeting conventional glycaemic control for type 2 diabetes mellitus. Cochrane Database Syst Rev 2013;11:CD008143

18. Gerstein HC, Miller ME, Ismail-Beigi F, et al.; ACCORD Study Group. Effects of intensive glycaemic control on ischaemic heart disease: analysis of data from the randomised, controlled ACCORD trial. Lancet 2014;384:1936-1941

19. Giorgino F, Leonardini A, Laviola L. Cardiovascular disease and glycemic control in type 2 diabetes: now that the dust is settling from large clinical trials. Ann N Y Acad Sci 2013;1281:36-50 20. Noh RM, Graveling AJ, Frier BM. Medically minimising the impact of hypoglycaemia in type 2 diabetes: a review. Expert Opin Pharmacother 2011;12:2161-2175

21. Landstedt-Hallin L, Englund A, Adamson U, Lins PE. Increased QT dispersion during hypoglycaemia in patients with type 2 diabetes mellitus. J Intern Med 1999;246:299-307

22. Sommerfield AJ, Wilkinson IB, Webb DJ, Frier BM. Vessel wall stiffness in type 1 diabetes and the central hemodynamic effects of acute hypoglycemia. Am J Physiol Endocrinol Metab 2007;293:E1274-E1279

23. Bonds DE, Miller ME, Bergenstal RM, et al. The association between symptomatic severe hypoglycaemia and mortality in type 2 diabetes: retrospective epidemiological analysis of the ACCORD study. BMJ 2010;340 b4909

24. Gerstein HC, Miller ME, Genuth $S$, et al. ACCORD Study Group. Long-term effects of intensive glucose lowering on cardiovascular outcomes. N Engl J Med 2011;364:818-828

25. Zoungas S, Patel A, Chalmers J, et al. ADVANCE Collaborative Group. Severe hypoglycemia and risks of vascular events and death N Engl J Med 2010;363:1410-1418

26. Zhang Z, Lovato J, Battapady H, et al. Effect of hypoglycemia on brain structure in people with type 2 diabetes: epidemiological analysis of the ACCORD-MIND MRI trial. Diabetes Care 2014;37:3279-3285

27. Bonds DE, Miller ME, Dudl J, et al. Severe hypoglycemia symptoms, antecedent behaviors, immediate consequences and association with glycemia medication usage: secondary analysis of the ACCORD clinical trial data. BMC Endocr Disord 2012;12:5

28. Punthakee Z, Miller ME, Launer LJ, et al.; ACCORD Group of Investigators; ACCORDMIND Investigators. Poor cognitive function and risk of severe hypoglycemia in type 2 diabetes: post hoc epidemiologic analysis of the ACCORD trial. Diabetes Care 2012;35:787-793 29. de Galan BE, Zoungas S, Chalmers J, et al.; ADVANCE Collaborative Group. Cognitive function and risks of cardiovascular disease and hypoglycaemia in patients with type 2 diabetes: the Action in Diabetes and Vascular Disease: Preterax and Diamicron Modified Release Controlled Evaluation (ADVANCE) trial. Diabetologia 2009;52:2328-2336

30. Chow LS, Chen H, Miller ME, Marcovina SM, Seaquist ER. Biomarkers related to severe hypoglycaemia and lack of good glycaemic control in ACCORD. Diabetologia 2015;58:1160-1166 31. Fonseca V, McDuffie R, Calles J, et al.; ACCORD Study Group. Determinants of weight gain in the action to control cardiovascular risk in diabetes trial. Diabetes Care 2013;36:21622168

32. van Dieren S, Czernichow S, Chalmers J et al. Weight changes and their predictors amongst 11140 patients with type 2 diabetes in the ADVANCE trial. Diabetes Obes Metab 2012;14:464-469

33. Reaven PD, Moritz TE, Schwenke DC et al.; Veterans Affairs Diabetes Trial. Intensive glucose-lowering therapy reduces cardiovascular disease events in veterans affairs diabetes trial participants with lower calcified coronary atherosclerosis. Diabetes 2009;58 2642-2648

34. Papademetriou V, Lovato L, Doumas $M$ et al.; ACCORD Study Group. Chronic kidney disease and intensive glycemic control increase cardiovascular risk in patients with type 2 diabetes. Kidney Int 2015;87:649-659

35. Calles-Escandón J, Lovato LC, SimonsMorton DG, et al. Effect of intensive compared with standard glycemia treatment strategies on mortality by baseline subgroup characteristics: the Action to Control Cardiovascular Risk in Diabetes (ACCORD) trial. Diabetes Care 2010;33 721-727

36. Duckworth WC, Abraira C, Moritz TE, et al.; Investigators of the VADT. The duration of diabetes affects the response to intensive glucose control in type 2 subjects: the VA Diabetes Trial. J Diabetes Complications 2011;25:355-361

37. Skyler JS, Bergenstal R, Bonow RO, et al. American Diabetes Association; American College of Cardiology Foundation; American Heart Association. Intensive glycemic control and the prevention of cardiovascular events: implications of the ACCORD, ADVANCE, and VA diabetes trials: a position statement of the American Diabetes Association and a scientific statement of the American College of Cardiology Foundation and the American Heart Association. Diabetes Care 2009;32:187-192 
38. American Diabetes Association. Glycemic targets. Sec. 6. In Standards of Medical Care in Diabetes-2015. Diabetes Care 2015;38(Suppl.): S33-S40

39. Riddle MC, Ambrosius WT, Brillon DJ, et al.; Action to Control Cardiovascular Risk in Diabetes Investigators. Epidemiologic relationships between $\mathrm{A} 1 \mathrm{C}$ and all-cause mortality during a median 3.4-year follow-up of glycemic treatment in the ACCORD trial. Diabetes Care 2010;33:983-990 40. Hempe JM, Liu S, Myers L, McCarter RJ, Buse JB, Fonseca V. The hemoglobin glycation index identifies subpopulations with harms or benefits from intensive treatment in the ACCORD trial. Diabetes Care 2015;38:1067-1074 41. Miller ME, Williamson JD, Gerstein HC, et al.; ACCORD Investigators. Effects of randomization to intensive glucose control on adverse events, cardiovascular disease, and mortality in older versus younger adults in the ACCORD Trial. Diabetes Care 2014;37:634-643

42. Perkovic V, Heerspink HL, Chalmers J, et al.; ADVANCE Collaborative Group. Intensive glucose control improves kidney outcomes in patients with type 2 diabetes. Kidney Int 2013;83: 517-523

43. Hirakawa Y, Arima H, Zoungas S, et al. Impact of visit-to-visit glycemic variability on the risks of macrovascular and microvascular events and allcause mortality in type 2 diabetes: the ADVANCE trial. Diabetes Care 2014;37:2359-2365

44. Zoungas S, Chalmers J, Neal B, et al.; ADVANCE-ON Collaborative Group. Follow-up of blood-pressure lowering and glucose control in type 2 diabetes. N Engl J Med 2014;371: 1392-1406

45. Hayward RA, Reaven PD, Wiitala WL, et al.; VADT Investigators. Follow-up of glycemic control and cardiovascular outcomes in type $2 \mathrm{di}$ abetes. N Engl J Med 2015;372:2197-2206

46. Tuomilehto J, Schwarz P, Lindström J. Longterm benefits from lifestyle interventions for type 2 diabetes prevention: time to expand the efforts. Diabetes Care 2011;34(Suppl. 2): S210-S214

47. Li G, Zhang P, Wang J, et al. The long-term effect of lifestyle interventions to prevent diabetes in the China Da Qing Diabetes Prevention Study: a 20-year follow-up study. Lancet 2008; 371:1783-1789

48. Eriksson KF, Lindgärde F. No excess 12-year mortality in men with impaired glucose tolerance who participated in the Malmö Preventive Trial with diet and exercise. Diabetologia 1998; 41:1010-1016

49. Tuomilehto J, Lindström J, Eriksson JG, et al.; Finnish Diabetes Prevention Study Group. Prevention of type 2 diabetes mellitus by changes in lifestyle among subjects with impaired glucose tolerance. N Engl J Med 2001; 344:1343-1350

50. Uusitupa M, Peltonen M, Lindström J, et al, Finnish Diabetes Prevention Study Group. Ten-year mortality and cardiovascular morbidity in the
Finnish Diabetes Prevention Study-secondary analysis of the randomized trial. PLoS One 2009;4:e5656

51. Ilanne-Parikka P, Eriksson JG, Lindström J, et al.; Finnish Diabetes Prevention Study Group. Effect of lifestyle intervention on the occurrence of metabolic syndrome and its components in the Finnish Diabetes Prevention Study. Diabetes Care 2008;31:805-807

52. The DECODE Study Group. Glucose tolerance and mortality: comparison of WHO and American Diabetes Association diagnostic criteria. The DECODE study group. European Diabetes Epidemiology Group. Diabetes Epidemiology: Collaborative analysis Of Diagnostic criteria in Europe. Lancet 1999;354:617-621

53. DECODE Study Group, European Diabetes Epidemiology Group. Is the current definition for diabetes relevant to mortality risk from al causes and cardiovascular and noncardiovascular diseases? Diabetes Care 2003;26:688-696

54. Lind M, Tuomilehto J, Uusitupa M, et al. The association between $\mathrm{HbAlc}$, fasting glucose, 1-hour glucose and 2-hour glucose during an oral glucose tolerance test and cardiovascular disease in individuals with elevated risk for diabetes. PLoS One 2014;9:e109506

55. Saito T, Watanabe M, Nishida J, et al. Zensharen Study for Prevention of Lifestyle Diseases Group. Lifestyle modification and prevention of type 2 diabetes in overweight Japanese with impaired fasting glucose levels: a randomized controlled trial. Arch Intern Med 2011;171 1352-1360

56. Rydén L, Grant PJ, Anker SD, et al.; Authors/ Task Force Members; ESC Committee for Practice Guidelines (CPG); Document Reviewers. ESC Guidelines on diabetes, pre-diabetes, and cardiovascular diseases developed in collaboration with the EASD: the Task Force on diabetes, pre-diabetes, and cardiovascular diseases of the European Society of Cardiology (ESC) and developed in collaboration with the European Association for the Study of Diabetes (EASD). Eur Heart J 2013;34:3035-3087

57. Chiasson JL, Josse RG, Gomis R, Hanefeld M Karasik A, Laakso M; STOP-NIDDM Trial Research Group. Acarbose treatment and the risk of cardiovascular disease and hypertension in patients with impaired glucose tolerance: the STOP-NIDDM trial. JAMA 2003;290:486-494 58. Holman RR, Bethel MA, Chan JC, et al.; ACE Study Group. Rationale for and design of the Acarbose Cardiovascular Evaluation (ACE) trial. Am Heart J 2014;168:23-9.e2

59. Califf RM, Boolell M, Haffner SM, et al. NAVIGATOR Study Group. Prevention of diabetes and cardiovascular disease in patients with impaired glucose tolerance: rationale and design of the Nateglinide And Valsartan in Impaired Glucose Tolerance Outcomes Research (NAVIGATOR) Trial. Am Heart J 2008; 156:623-632
60. Yates T, Haffner SM, Schulte PJ, et al. Association between change in daily ambulatory activity and cardiovascular events in people with impaired glucose tolerance (NAVIGATOR trial): a cohort analysis. Lancet 2014;383: 1059-1066

61. Home PD. A common fallacy of observational medication studies in diabetes. Diabetes Obes Metab 2015;17:317-318

62. Inzucchi SE, Bergenstal RM, Buse JB, et al. Management of hyperglycemia in type 2 diabetes, 2015: a patient-centered approach: update to a position statement of the American Diabetes Association and the European Association for the Study of Diabetes. Diabetes Care 2015 38:140-149

63. UK Prospective Diabetes Study (UKPDS) Group. Effect of intensive blood-glucose control with metformin on complications in overweight patients with type 2 diabetes (UKPDS 34). Lancet 1998;352:854-865

64. Kahn SE, Haffner SM, Heise MA, et al.; ADOPT Study Group. Glycemic durability of rosiglitazone, metformin, or glyburide monotherapy. N Eng J Med 2006;355:2427-2443

65. GlaxoSmithKline. Advisory committee briefing document: cardiovascular safety of rosiglitazone [Internet], 2007. Available from www.fda.gov/ohrms/dockets/ac/07/briefing/ 2007-4308b1-01-sponsor-backgrounder.pdf Accessed 6 January 2012

66. Home PD, Pocock SJ, Beck-Nielsen $\mathrm{H}$, et al.; RECORD Study Team. Rosiglitazone evaluated for cardiovascular outcomes in oral agent combination therapy for type 2 diabetes (RECORD) a multicentre, randomised, open-label trial. Lancet 2009;373:2125-2135

67. Hanefeld M, Cagatay M, Petrowitsch $T$, Neuser D, Petzinna D, Rupp M. Acarbose reduces the risk for myocardial infarction in type 2 diabetic patients: meta-analysis of seven long-term studies. Eur Heart J 2004;25:10-16 68. Mahaffey KW, Hafley G, Dickerson S, et al. Results of a reevaluation of cardiovascular outcomes in the RECORD trial. Am Heart J 2013; 166:240-249.e1

69. Scirica BM, Bhatt DL, Braunwald $E$, et al. SAVOR-TIMI 53 Steering Committee and Investigators. Saxagliptin and cardiovascular outcomes in patients with type 2 diabetes mellitus. N Engl J Med 2013;369:1317-1326

70. White WB, Cannon CP, Heller SR, et al. EXAMINE Investigators. Alogliptin after acute coronary syndrome in patients with type 2 diabetes. N Engl J Med 2013;369:1327-1335 71. Green JB, Bethel MA, Armstrong PW, et al.; TECOS Study Group. Effect of sitagliptin on cardiovascular outcomes in type 2 diabetes. N Eng J Med 2015;373:232-242

72. Zinman B, Wanner C, Lachin JM, et al.; EMPAREG OUTCOME Investigators. Empagliflozin cardiovascular outcomes, and mortality in type 2 diabetes. N Engl J Med 2015;373: 2117-2128 